\title{
Literatur
}

1. Held, E., O. Hoefrele, G. Reich, U. Stein, E. Werizies und E. BUDDECKE, diese Z., vorstehend. - 2. KAPLAN, D. und $K$. MeYer, Proc. Soc. exper. Biol. Med. N.Y. 105, 78 (1960). BudDECKE, E. J. Atheroscler. Res. 2, 32 (1962). - 3. Hauss, W. H., Verh. Dtsch. Ges. inn. Med., 69, 554 (1963). Hauss, W. H. und G. JUNGE-HüLsing, Dtsch. med. Wschr. 86, 763 (1961). - 4. BuDDecke E. und D. Platt, diese Z., 3, 4 (1965). - 5. Burton, K., Biochem. J. 62, 315 (1956). - 6. Kaltwasser, F., P. Wolters und J. PIEper, Clin. chim. Acta (Amsterdam) 15, 347 (1967). 7. MEYer, W. W., Virchows Arch. path. Anat. 320, 67 (1951). 8. Filipovic, I. und E. BudDECKE, Hoppe-Seylers Z. physiol. Chem. im Druck. - 9. AdAMrs, C. W. M., Vascular Histochemistry, S. 33.
LLOYX-LUKe, Ltd., London (1967). - 10. ZEMPLÉNYX, T., Z. LojDA u. O. Mrhová, Atherosclerosis and its Origin, S. 504, ed. by M. Sandler u. G. H. Bourne, Academic Press., New York (1963). '11. Reich, G., Dissertation (Math.-Naturwiss. Fakultät, Univ. Tübingen) (1966). Hozfere, O., Dissertation (Math.-Naturwiss. Fakultät, Univ. Tübingen) (1966). -12. KIRK, J. E., J. Gerontol. 17, 158 (1962). - 13. BRANwORd, A. W. und C. J. CARR, Lancet II, 1254 (1960). - 14. DYrraye M. und J. E. KIRK, J. Gerontol. 11, 33 (1956). - 15. Platit, D., Klin. Wschr. 45, 92 (1967). 16. Haușs, H. W., G. Junge-Hülsing, K. J. Matthes und W. WrRTH, J. Atheroscler. Res. 5, 451 (1965).
Prof. Dr. E. Buddecke 44 Münster (Westf.) Waldeyerstraße 15

\section{Eine automatisierte Bestimmung von anorganischem Phosphat}

\author{
Von G. F. Hoppe-SEYLER und G. GundLACH \\ Aus der Klinisch-Chemischen Abteilung (Leiter: Priv.-Doz. Dr. G. Gundlach) der Urologischen Üniversitätsklinile \\ Homburg/Saar (Direktor: Prof. Dr. C. E. Alken)
}

(Eingegangen am 13. Dezember 1967)

\section{Herrn Prof. Dr. Dr. Ernst Schütte qum 60. Geburtstag qugeeignet}

Eine einfache, empfindliche, automatisierte Methode zur Bestimmung des anorganischen Phosphates in Serum, Harn und biologischen Flüssigkeiten wird beschrieben. Der Molybdänphosphorsäurekomplex wird durch Hydrazinsulfat bei $95^{\circ}$ reduziert.

Eine Modifikation der angegebenen Technik erlaubt die automatische Bestimmung sehr gẹtinger P-Konzentrationen $(0,05$ ppm P).

Die Interferenz stabiler Phosphatester und anderer Substanzen wird diskutiert.

A simple, sensitive, automated method is described for the determination of inorganic phosphate in serum, urine, and other biological fluids. The molybdenum-phosphoric acid complex is reduced by hydrazine sulphate at $95^{\circ}$.

The method can be modified for the automatic determination of very low phosphate concentrations $(0.05 \mathrm{ppm} . \mathrm{P})$. Interference by stable phosphate estets and other substances is discussed.

Die Grundlage der gebräuchlichen Phosphatbestimmungen ist die Reduktion der Molybdänphosphorsäure zu Molybdänblau. Empfindlichkeitsunterschiede der einzelnen Methoden beruhen auf der Verwendung verschiedener Reduktionsmittel. Für die automatische Bestimmung wird das Verfahren nach FISKE und SubBARow mit dem Reduktionsmittel 1, 2, 4-Aminonaphtholsulfosäure empfohlen $(1,2)$.

Voraussetzung für die Anwendung einer Methode in der klinisch-chemischen Routine und zur Durchführung von Reihenuntersuchungen ist die exakte Reproduzierbarkeit der Meßwerte und eine gute Haltbarkeit der Reagenzien. Dieser Forderung entspricht die Reaktion nach Bolz und Mellon (3), die Hydrazinsulfat als Reduktionsmittel verwendet, einen mindestens $12 \mathrm{Stdn}$. haltbaren Farbkomplex bildet und gegenüber dem vorgenannten Verfahren den Vorteil höherer Empfindlichkeit hat (4).

\section{Material und Methoden \\ Reagenzien}

Schwefelsäure p. a. (Merck 731)

Ammoniummolybdat (Merck 1182)

Hydrazinsulfat (Merck 4602)

Salzsäure p. a. (Merck 317)
Lösungen

A. Methode für Serum (10-100 ppm P)

1. $\mathrm{Zu} 4500 \mathrm{~m} l$ dest. Wasser werden $270 \mathrm{~m} l$ Schwefelsäure gegeben. Nach Mischen und Abkühlen ${ }^{1}$ ) der Lösung fügt man $30,0 \mathrm{~g}$ Ammoniummolybdat zu.: Auffüllen mit dest. Wasser auf $5000,0 \mathrm{ml}$.

2. 0,4 proz. Hydrazinsulfat

3. $1 \mathrm{~N} \mathrm{HCl}$

B. Mikromethode (0,05-1 ppm P)

1. $\mathrm{Zu} 4000 \mathrm{~m} l$ dest. Wasser werden $665 \mathrm{~m} l$ Schwefelsäure gegeben. Nach Mischen und Abkühlen ${ }^{1}$ ) der Lösung fügt man $100,0 \mathrm{~g}$ Ammoniummolybdat zu. Auffüllen mit dest. Wasser auf $5000,0 \mathrm{ml}$.

2. 1 proz. Hydrazinsulfat

3. 0,18 proz. $\mathrm{HCl}$

\section{Ausfübrung}

A. Methode für Serum

Das Verhältnis der Reagenzmengen zueinander geht aus Abbildung 1a hervor, wobei die Zablenangaben an den Pumpschläuchen den geförderten $\mathrm{m} / / \mathrm{Min}$. entsprechen. Reagenzkonzentrationen s. Lösúngen.

1) Es ist unbedingt erforderlich zuerst die Schwefelsäurelösung herzustellen und vor Zugabe des Ammoniummolybdatemolybdates gut abkühlen zu lassen. Die Reagenzlösungen sind dann in jeder Konzentration beständig. 

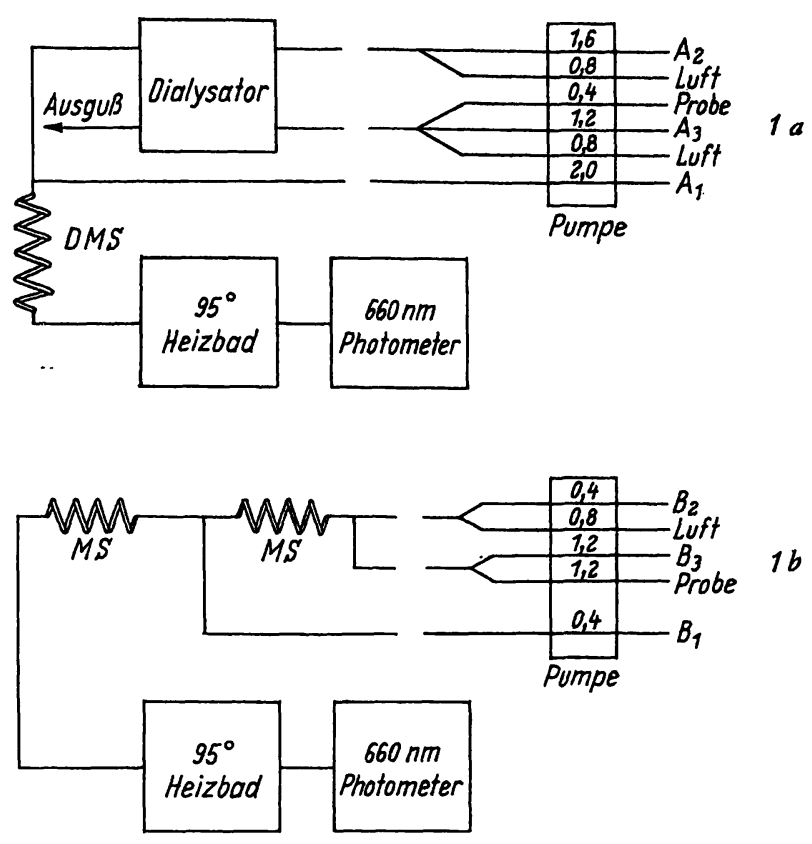

Abb. $1 a$

Aufbau der Autoanalyzereinheit (Methode für Serum)

Die Zahlenangaben an den Pumpschläuchen geben die geförderte Reagenzmenge ( $\mathrm{m} / \mathrm{Min}$.$) an$

MS = doppelte Mischspirale

Probenfrequenz bis $60 /$ Std.

Die Pumpschläuche entsprechen dem Technicon-AutoanalyzerSystem

\section{Abb. 16}

Aufbau der Autoanalyzereinheit (Mikromethode)

$\mathrm{B}_{2}, \mathrm{~B}_{2}, \mathrm{~B}_{3}=$ Reagenzlösungen (s. Methodik $\mathrm{B}$ )
Die Zahlenangaben an den Pumpschläuchen geben die geförderte Reagenzmenge (ml/Min.) an $M S=$ einfache Mischspirale
Probenfrequenz bis 60/Min.

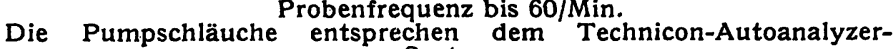
System

Die mit Salzsäure versetzte Probe wird im Dialysator gegen Hydrazinsulfat dialysiert. Danach wird dem Dialysat Ammoniummolybdatlösung zugepumpt und in einer Glasspirale gemischt. Die Reduktion der Phosphormolybdänsäure findet beim Durchlaufen der Probe durch das Heizbad bei $95^{\circ}$ statt. (Erhitzungsdauer $7 \mathrm{Min}$.) Die Extinktion der gebildeten Farblösung wird mit Hilfe eines Doppelstrahlkolorimeters bei $660 \mathrm{~nm}$ registriert.

\section{B. Mikromethode}

Abbildung $1 b$ stellt eine Arordnung dar, die unter Verwendung anderer Reagenzkonzentrationen den Nachweis sehr geringer Phosphatkonzentrationen gestattet. Die Steigerung der Empfindlichkeit wird durch Änderung des Proben-Reagenzverhältnisses und Fortlassen des Diälysators erreicht.

\section{Ergebnisse und Diskussion}

Die beschriebene Methode ist in bezug auf Änderung der Reagenzkonzentrationen wenig empfindlich. Dies hat insbesondere dann eine Bedeutung, wenn - z. B. durch Alterung der Pumpschläuche - ein gleichmäßiges Reagenzverhältnis nicht gewährleistet ist.

Aus Tabelle 1 geht hervor, daß Änderungen der Ammoniummolybdatkonzentration um $50 \%$, der $\mathrm{Hy}$ drazinsulfatkonzentration $z$ wischen $0,1 \%$ und $1 \%$ oder der Schwefelsäurekonzentration zwischen $0,5 \mathrm{~N}$ und $3 \mathrm{~N}$ die Farbbildung nicht wesentlich beeinflussen. Lediglich im unteren Konzentrationsbereich findet sich bei der Summierung über sämtliche Werte ein Variationskoeffizient von $12 \%$. Eine Erhöhung der Ammoniummolybdatkonzentration in dem angegebenen Bereich fübrt zu einer geringen Verminderung der Extinktionen. Eine Erhöhung der Farbausbeute kann durch Senkung der Säurekonzentration oder Erhöhung der Hydrazinsulfatkonzentration erreicht werden. Die von uns gewählten Konzentrationen gewährleisten eine gute Reproduzierbarkeit in der Serie, wie auch von Tag zu Tag. In einer Serie von $138 \mathrm{Meßwerten} \mathrm{(Tab.} \mathrm{2)} \mathrm{ergibt} \mathrm{sich}$ eine Abweichung der ersten $20 \mathrm{Meßwerte} \mathrm{gegenüber} \mathrm{den}$ letzten 20 Werten von $0,6 \%$. Der Variationskoeffizient ist $<1 \%$. Die Drift in diesem Experiment bleibt innerhalb der Standardabweichung der einzelnen Meßwerte. Der statistischen Auswertung der Reproduzierbarkeit von Tag zu Tag lagen jeweils 40 Meßwerte zugrunde. Die Reagenzlösungen wurden während der gesamten Versuchszeit nicht verändert oder neu angesetzt. Die

Tab. 2

Untersuchungen zur Reproduzierbarkeit innerhalb der Serie und von Tag zu Tag $(n=40 / \mathrm{Tag})$

\begin{tabular}{|c|c|c|c|}
\hline Probe & $\begin{array}{l}\text { Gefundener } \\
\text { Mittelwert } \\
\text { ppm P }\end{array}$ & $\stackrel{\text { s }}{\text { ppm } P}$ & $\mathrm{~V} \%$ \\
\hline $\begin{array}{r}1-20 \\
1-138 \\
119-138\end{array}$ & $\begin{array}{l}30,1 \\
30,0 \\
29,9\end{array}$ & $\begin{array}{l}0,16 \\
0,23 \\
0,24\end{array}$ & $\begin{array}{l}0,53 \\
0,77 \\
0,80\end{array}$ \\
\hline $\begin{array}{c}\text { Tag } \\
1 \\
2 \\
3 \\
4 \\
5 \\
6 \\
7 \\
8 \\
9 \\
10\end{array}$ & $\begin{array}{l}30,3 \\
29,7 \\
29,3 \\
29,7 \\
30,3 \\
29,4 \\
30,3 \\
30,2 \\
30,7 \\
30,2\end{array}$ & $\begin{array}{l}0,15 \\
0,19 \\
0,20 \\
0,10 \\
0,10 \\
0,07 \\
0,12 \\
0,10 \\
0,08 \\
0,08\end{array}$ & $\begin{array}{l}0,50 \\
0,64 \\
0,68 \\
0,33 \\
0,32 \\
0,23 \\
0,40 \\
0,32 \\
0,25 \\
0,23\end{array}$ \\
\hline Mittelwert: & 30,0 & 0,14 & 0,39 \\
\hline
\end{tabular}

Tab. 1

Abhängigkeit der Farbausbeuten (E $660 \mathrm{~nm}$ ) von verschiedenen Reagenzkonzentrationen

$\overline{\mathbf{x}}$ : Mittelwert; s: Standardabweichung; V: Variationskoeffizient

\begin{tabular}{|c|c|c|c|c|c|c|c|c|c|c|c|c|c|}
\hline \multirow{3}{*}{$\begin{array}{c}\text { ein- } \\
\text { gesetzt } \\
\text { P } \\
\text { ppm }\end{array}$} & \multicolumn{3}{|c|}{$\begin{array}{l}\text { Hỳdrazinsulfat } 0,4 \% \\
\text { Schwefelsäure iN }\end{array}$} & \multicolumn{4}{|c|}{$\begin{array}{l}\text { Konstante Reagenzkonzentration } \\
\text { Ammoniummolybdat } 0,6 \% \\
\text { Schwefelsäure iN }\end{array}$} & \multicolumn{3}{|c|}{$\begin{array}{ll}\text { Ammoniummolybdat } & 0,6 \% \\
\text { Hydrazinsulfat } & 0,5 \%\end{array}$} & \multicolumn{3}{|c|}{ gefunden } \\
\hline & \multirow{2}{*}{\multicolumn{3}{|c|}{$\underset{0,4}{\text { Ammoniummolybdat }} \mathrm{0}, \mathrm{0}$}} & \multicolumn{4}{|c|}{ Variierte Reagenzkonzentration } & \multirow{2}{*}{\multicolumn{3}{|c|}{$3{ }_{2}^{\text {Schwefelsäure } N}{ }_{0,5}$}} & $\begin{array}{c}x \\
\mathrm{ppm}\end{array}$ & $\begin{array}{c}\mathrm{s} \\
\mathrm{ppm}\end{array}$ & $\begin{array}{l}\mathrm{V} \\
\%\end{array}$ \\
\hline & & & & 0,1 & $\underset{0,3}{\text { Hydraz }}$ & $\begin{array}{r}\text { isulfat } \\
0,7\end{array}$ & 1,0 & & & & & & \\
\hline $\begin{array}{r}10 \\
30 \\
50 \\
60 \\
100\end{array}$ & $\begin{array}{l}0,088 \\
0,297 \\
0,500 \\
0,600 \\
1,010\end{array}$ & $\begin{array}{l}0,081 \\
0,292 \\
0,505 \\
0,575 \\
0,990\end{array}$ & $\begin{array}{l}0,079 \\
0,289 \\
0,500 \\
0,550 \\
0,980\end{array}$ & $\begin{array}{l}0,089 \\
0,298 \\
0,500 \\
0,580 \\
1,000\end{array}$ & $\begin{array}{l}0,093 \\
0,308 \\
0,510 \\
0,580 \\
1,000\end{array}$ & $\begin{array}{l}0,112 \\
0,333 \\
0,535 \\
0,625 \\
1,050\end{array}$ & $\begin{array}{l}0,112 \\
0,333 \\
0,535 \\
0,636 \\
1,040\end{array}$ & $\begin{array}{l}0,083 \\
0,310 \\
0,495 \\
0,580 \\
0,980\end{array}$ & $\begin{array}{l}0,087 \\
0,291 \\
0,484 \\
0,575 \\
0,960\end{array}$ & $\begin{array}{l}0,097 \\
0,303 \\
0,500 \\
0,580 \\
0,980\end{array}$ & $\begin{array}{r}10 \\
30 \\
50 \\
60 \\
100\end{array}$ & $\begin{array}{l}1,1 \\
1,6 \\
1,6 \\
2,6 \\
4,1\end{array}$ & $\begin{array}{l}11 \\
5,3 \\
3,2 \\
4,3 \\
4,1\end{array}$ \\
\hline
\end{tabular}


Ergebnisse ergaben sich durch direkte Berechnung aus den Extinktionswerten bei $660 \mathrm{~nm}$. Es wurden also nicht täglich Eichkurven angelegt.

Der Variationskoeffizient der insgesamt 400 Einzelmessungen würde also auch von etwa auftretenden Veränderungen der Reagenzlösungen mitbeeinflußt werden. Die so erhaltenen Werte weichen von dem Mittelwert aller Werte um höchstens $2,5 \%$ bei einem Variationskoeffizienten von $0,4 \%$ ab. Dieser systematische Fehler weist keine Drift auf und läßt sich, wie schon aus dem Variationskoeffizienten der in Tabelle 2 angeführten Serien hervorgeht, durch tägliche Kontrollanalysen verringern.

Uber den gesamten Meßbereich zwischen 0 und 100 ppm $P$ herrscht Linearität (Abb. 2). Bei der Darstellung dieser Eichkurve wurden die gefundenen maximalen $\mathrm{Ab}-$ weichungen auch bei den in Tabelle 1 angegebenen Änderungen der Reagenzzusammensetzung berücksichtigt, stellen also die ungünstigsten Verhältnisse dar. Während Phosphatester vom Typ der Glycerinphosphorsäure zu weniger als $0,5 \%$ erfaßt werden, zeigen Polyphosphate unter den beschriebenen Bedingungen eine erhebliche Farbbildung. So wird Pyrophosphorsäure nahezu quantitativ, die Triphosphorsäure zu $80 \%$, die Tetraphosphorsäure zu 60\% erfaßt, während Polymetaphosphat 20\% Farbausbeute, bezogen auf Orthophosphat, ergibt. Diese Verbindungen finden sich jedoch nicht oder im Verhältnis zu anorganischem Orthophosphat nur in einem verschwindend geringen Anteil in physiologischen Flüssigkeiten.

Bei der Reduktion der Phosphormolybdänsäure durch Eisen (II)-sulfat stören Komplexbildner die Reaktion (5). Die Anwesenheit von z. B. einer $40 \mathrm{~mm}$ MannitolLösung setzt die Farbausbeute um $40 \%$ herab. Diese Schwierigkeit tritt bei der Reduktion mit Hydrazinsulfat nicht auf. Die Farbausbeute wird in Gegenwart einer $50 \mathrm{~mm}$ Mannitol-Lösung nicht meßbar beeinträchtigt. Erst bei Gegenwart einer 0,5M Lösung dieser Substanz sinkt die Farbausbeute um 5,1\%.

Durch Fortlassen des Dialysators und Änderung des Fließsystems lassen sich in eiweißfreien Lösungen Phosphatbestimmungen bis herab zu 0,05 ppm P durchführen. Die Empfindlichkeit beträgt dabei $0,02 \mathrm{ppm}$. Dies bedeutet, daB sich nach der chromatographischen Abtrennung des Orthophosphates noch sehr geringe Mengen an Pyrophosphat und anderen Polyphosphaten bestimmen lassen. Außerdem entfällt die für solche geringen Mengen von Phosphat als notwendig er-

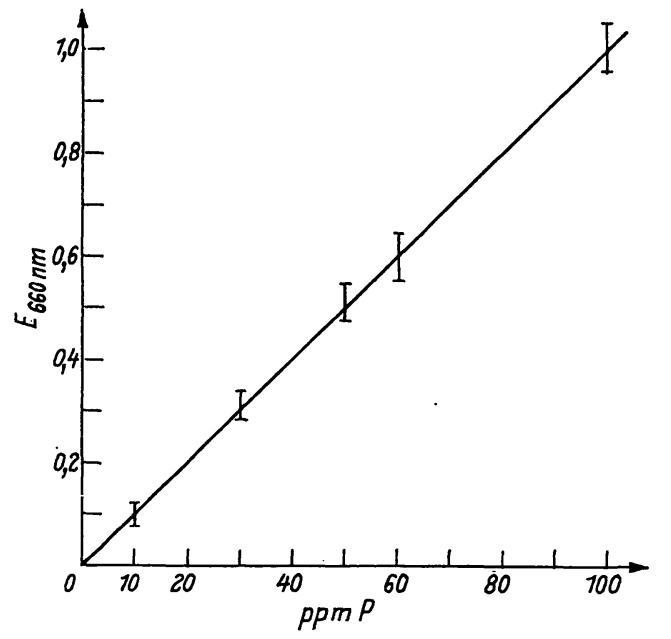

Abb. 2

Eichkurve zur Bestimmung des anorganischen Phosphates Die Meß̈werte wurden bei verschiedenen Reagenzkonzentrationen gewonnen und stellen die maximal gefundene Abweichung dar (Tab. 1)

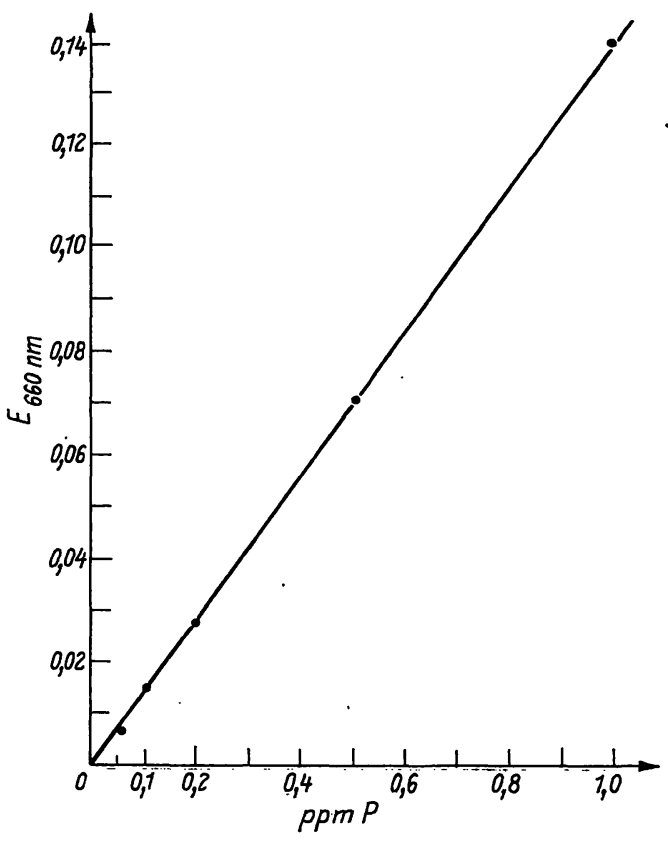

Abb. 3

Eichkurve für die Bestimmung von anorganischem Phosphat im Mikromaßstab

achtete Extraktion zur Anreicherung der Phosphormolybdänsäure (6).

Die Reagenzien für beide beschriebenen Methoden sind bei Raumtemperatur lange Zeit stabil. Im Autoanalyzer wird keine Zugabe von Netzmitteln für einen gleichmäßigen Durchfluß benötigt.

\section{Literatur}

1. FISKe, C. H. und J. SubBarow, J. biol. Chemistry 66, 375 (1925). - 2. Technicon Autoanalyzer Methodology N-4b. - 3. BoLz, D. F. und M. G. M. Melion, Analytic. Chem. 19, 873 (1947). 4. Goodwin, S. F., R. Thibert, D. McCann und A. J. Borre,
Analytic. Chem. 30, 1097 (1958). - 5. Vreman, H. J. und F. F. 'Jöвsis, Analytic. Biochem. 17, 108 (1966). - 6. KIRSTEN, W. S., Microchemical J. 12, 307 (1967).

Dr. G. Hoppe-Seyler u. Dr. G. Gundlach 665 Homburg/Saar

Urologische Universitätsklinik 